\title{
Revisitando as mobilidades turísticas
}

\author{
Thiago Allis \\ Camila Maria dos Santos Moraes ${ }^{b}$ \\ Mimi Sheller
}

\section{Resumo}

Este artigo, de caráter ensaístico, tem por objetivos apresentar e discutir elementos essenciais para o estudo do turismo e das mobilidades, tendo por referência o paradigma das novas mobilidades. 0 argumento central do trabalho - que tem por base a tradução e ampliação de capítulo inicial do livro Tourism Mobilities: places do play, places in play (Sheller \& Urry, 2004) - é que o turismo se desenvolve a partir da elaboração (ou invenção) lugares turísticos (places to play). Mas, ao mesmo tempo e de maneira metafórica, também os lugares estão em movimento (places in play), indicando que a mobilidade de estilos de vida, visões de mundo e narrativas dão forma a este fenômeno conectado globalmente. 0 trabalho também dialoga com as reflexões de John Urry sobre futuros, especialmente nas críticas à alta dependência dos derivados do petróleo nas sociedades capitalistas. Ainda que não seja o enfoque do texto, encerra com algumas reflexões sobre o futuro do turismo em um contexto (pós-)pandêmico, em que as mobilidades turísticas estarão potencialmente influenciadas por revisões nos novos protocolos sanitários e pela possível emergência de novos estilos e demandas de viagem.

Palavras-chave: Mobilidades; Sociologia do turismo; Teorias do turismo, Destinação turística

\section{Abstract \\ Revisiting tourism mobilities}

This essay aims to present and discuss key elements for the study of tourism and mobilities, as understood within the New Mobilities Paradigm. The central argument of this paper - based on the translation and extension of the introductory chapter of the book Tourism Mobilities: places do play, places in play (Sheller \& Urry, 2004) - is that tourism develops from the elaboration (or invention) of tourist places (places to play). But, at the same time, metaphorically places are also on the move (places in play), indicating the mobility of lifestyles, worldviews and narratives that shape the flux of globally connected destinations. The work is also in dialogue with John Urry's reflections

a. Doutor em Arquitetura e Urbanismo pela Universidade de São Paulo. Docente do Bacharelado em Lazer e Turismo e do Programa de Pós-Graduação em Turismo na Universidade de São Paulo, São Paulo, Brasil. E-mail: thiagoallis@usp.br.

b. Doutora em História, Política e Bens Culturais na Fundação Getúlio Vargas,Rio de Janeiro, Brasil. Docente nos cursos de Bacharelado em Turismo, Licenciatura em Ciências Sociais, Mestrado em Ecoturismo e Conservação e Mestrado e Doutorado em Memória Social na Universidade Federal do Estado do Rio de Janeiro, Rio de Janeiro, Rio de Janeiro, Brasil. E-mail: camila.moraes@unirio.br.

c. Doutora em Sociology and Historical Studies pela New School for Social Research, Nova Iorque, Nova Iorque, Estados Unidos. Docente no curso de Sociologia na Drexel University, Filadélfia, Pensilvânia, Estados Unidos. E-mail: mbs67@drexel.edu. 
on futures, especially the criticism of the highly carbon-dependent capitalist society. The article ends with some reflections on the future of tourism in a (post-)pandemic context, in which tourism mobilities will potentially be influenced by the introduction of new health protocols and the likely emergence of new travel styles and demands.

Keywords: Mobilities; Sociology of tourism; Tourism theories; Tourism destination

\section{Resumen}

\section{Revisitando las movilidades turísticas}

El objetivo principal de este ensayo es el de presentar y discutir elementos esenciales para el estudio del turismo y de las movilidades, a través del Paradigma de las Nuevas Movilidades. El argumento central del trabajo - que está basado en la traducción y extensión de un capítulo introductório del libro Tourism Mobilities: places do play, places in play (Sheller \& Urry, 2004) - es que el turismo se desarrolla a partir de la creación (o invención) de lugares turísticos (places to play). Al mismo tiempo y de manera metafórica, los lugares también se mueven (places in play), indicando movilidad de estilos de vida, visiones del mundo y narrativas que moldan este fenómeno conectado globalmente. Asimismo, el trabajo dialoga con las reflexiones de John Urry acerca de futuros, respecto a la gran dependencia de los recursos derivados del petróleo en las sociedades capitalistas. Aunque no sea este el enfoque del texto, concluimos con reflexiones sobre el futuro del turismo en un contexto pós-pandémico, en el cual las movilidades turísticas estarán potencialmente influenciadas por la introducción de nuevos protocolos sanitarios y por una posible emergencia de nuevos estilos y demandas de viajes.

Palabra-clave: Movilidades; Sociología del turismo; Teorías del turismo; Destinación turística.

\section{TURISMO E MOBILIDADES: UMA RELAÇÃO ÓBVIA?}

O livro Tourism Mobilities: places to play, places in play foi publicado em 2004 pela editora Routledge, no idioma inglês, na forma de coletânea com 18 capítulos. A obra se propunha a lançar luz sobre o turismo pelas lentes das mobilidades, em um momento em que ainda pouco se falava sobre turismo como de manifestação complexa das mobilidades - inclusive porque um novo paradigma ou um giro estava em elaboração (como, em realidade, ainda está).

John Urry, decano dos estudos de mobilidades nessa perspectiva, vinha elaborando ao longo da década de 1990 boa parte das ideias que alimentariam uma nova escola de pensamento. De fato, a edição das obras Sociology beyond societies: Mobilities for the twenty-first century (Urry, 2000) e depois Mobilities (Urry, 2007) trilharam o caminho para muitas das reflexões sobre mobilidades, relevantes até hoje. 0 argumento central era de que as diversas mobilidades e suas complexas conexões apontavam para a necessidade de repensar o "social como sociedade" para um "social como mobilidade" (Urry, 2000 p. 2). Como forma de enraizar novas pesquisas por este olhar, em 2003, junto com Mimi Sheller e outros pesquisadores, ele funda o Centre for Mobilities Research (CeMoRe), no Departamento de Sociologia, da Universidade de Lancaster, considerado, até hoje, um think tank global no assunto.

De maneira muito curiosa, parte da elaboração teórica sobre as mobilidades turísticas parecem ter nascido - ainda que, naquele momento, de maneira epistemologicamente inconsciente - com a publicação de Olhar do Turista, em 1990. 
Este foi o único livro do sociólogo traduzido para o português (Urry, 1996), sendo um dos de maior influência e longevidade para o ensino de turismo no país, especialmente ao abordar a atividade como fenômeno social em perspectiva histórica - ainda que bastante centrada na realidade europeia. A esta se segue uma série de obras que tratam de turismo, a saber: Economies of signs and space (Lash \& Urry, 1993), Consuming places (Urry, 1995), Touring cultures (Urry \& Rojek, 1997), Contested Natures (Macnaghten \& Urry, 1998), a segunda edição de The Tourist Gaze (Urry, 2002) e The Tourist Gaze 3.0 (Larsen \& Urry, 2011). Em todas elas, há pistas do pensamento sobre mobilidades, sobre o qual Urry se dedicaria nos anos seguintes (Moraes, 2018).

A partir do encontro de John Urry e Mimi Sheller, no recém-fundado CeMoRe, produziu-se Tourism Mobilities (Sheller \& Urry, 2004). Podemos dizer que o olhar do turista encontrou o olhar sobre os destinos turísticos ou ainda, que a sociologia do turismo britânica encontrou a americana. Se Urry focava seus estudos na Inglaterra, mais especificamente sobre a ascensão e queda de destinos britânicos, Sheller se dedicava e ainda se dedica aos estudos sobre o Caribe como destino turístico e espaço de produção e reprodução de desigualdades sociais, trazendo uma nova perspectiva para a sociologia do turismo americana. 0 grande resultado deste encontro é a coletânea e a superação da dicotomia dos estudos do turismo. Não caberiam mais os estudos sobre o turista ou sobre os lugares turísticos: ambos estão imbricados em uma complexa rede de sistemas que são profundamente estudados segundo as lentes das mobilidades (Moraes, 2017).

Na sequência, o artigo New Mobilities Paradigm (Sheller \& Urry, 2006) se apresenta como um divisor de águas nos estudos de mobilidade como tema central para as ciências sociais. 0 texto é quase um manifesto em prol das múltiplas mobilidades tanto como objeto, mas especialmente como enfoque teórico-metodológico. Era preciso - urgiam os autores - mobilizar as ciências sociais, superando uma mirada estática e reconhecendo que as relações sociais são direta e indiretamente definidas pelas (i)mobilidades.

Muito se desenvolveu - e continua se desenvolvendo - sob a égide de um novo paradigma ou de um giro epistêmico (Freire-Medeiros et al, 2018; Sheller, 2014; Cresswell, 2010; Kaufmann, 2009; Hannam et al., 2006; Sheller \& Urry, 2006), com o entendimento de que as mobilidades são fato central na vida moderna e pós-moderna, o que leva a novas "formas de pensar e teorizar as mobilidades (de pessoas, de ideias, de coisas) (Cresswell, 2010, p. 551)". Agora, multiplicam-se eventos, publicações, grupos de pesquisa que se dedicam de maneira mais específica ao estudo das mobilidades, como as revistas Mobilities (2006), Tranfers (2011) e Applied Mobilities (2016), e, no contexto latino-americano, a coletânea Términos Clave de Movilidades en América Latina (Singh et al., 2018) e as duas edições da Escola de Ciência Avançada em Mobilidades (SPMob), organizadas na Universidade de São Paulo em 2017 e 2019 - sendo que a edição de 2017 resultou no Dossiê Mobilidades, da Revista Tempo Social. Em que pese o turismo, a abertura de um grupo de trabalho sobre mobilidades e turismo nos seminários anuais da Associação de Pós-Graduação e Pesquisa em Turismo (ANPTUR) representa esforços e avanços de reflexão e difusão desta interface.

0 longo deste processo, turismo e mobilidades foram se imbricando de maneira incidental na literatura, ainda que suas conexões de origem pareçam 
muito explícitas (ver, por exemplo, Coles et al., 2005; Hall 2004; Hannam et al., 2014; Coles, 2015; Hall, 2015). Por isso, uma vez que a produção sobre mobilidades turísticas percorre um caminho relativamente inespecífico - mesmo com contribuições inclusive a partir do Brasil (Nogueira \& Moraes, 2020; Allis, 2016; Kunz, 2014) -, entendemos que os fundamentos discutidos em Tourism Mobilities ainda podem contribuir para um direcionamento de trabalhos e pesquisas neste campo.

Com efeito, o livro poderia ser entendido quase como retorno a uma relação de origem (turismo/mobilidade), mesmo quando a obra deixa claro que se trata ainda de uma mirada em processo. Afinal, poucos discordariam que turismo é produto das muitas dimensões de mobilidades, mas raramente tratado e estudado como tal - e este é um princípio que perpassa a obra e os estudos sobre mobilidades turísticas desde então.

Sendo uma coletânea, produzida em um momento de poucas publicações que buscavam enfocar turismo pelo prisma das mobilidades, o livro traz em seu primeiro capítulo um conjunto de abordagens que poderiam ser consideradas um bom plano de voo para as pesquisas na área. A coletânea proporciona um conjunto de casos - tratando de dimensões e objetos clássicos para os estudos em turismo (a praia, a natureza, a favela, o sítio arqueológico, o centro histórico etc.), que, mesmo datados, ilustram tentativas de analisar o turismo por perspectivas pouco recorrentes nos estudos de turismo (naquela época e, talvez, ainda hoje). As menções a todos os capítulos subsequentes do livro foram mantidas e encontram-se nas referências bibliográficas do artigo.

Claro que há muitas produções acadêmicas e publicações depois disso, mas, com o objetivo de aproximar mais seu conteúdo a leitores da Língua Portuguesa, a tradução e ampliação deste primeiro capítulo de Tourism Mobilities pode estimular pesquisadoras e pesquisadores a dedicar parte de suas atenções para este não muito longo, porém auspicioso percurso teórico-metodológico. Assim, a ideia subjacente é que mobilidades turísticas possam se consolidar como campo de análise - para além de objeto específico ou mera adjetivação.

0 título original do livro (Tourism Mobilities: places to play, places in play) se vale da polissemia do termo play na Língua Inglesa, impossível de transpor, com as mesmas intenções e resultados, para a Língua Portuguesa. Daí a opção por aproximar a tradução, mas com o cuidado de manter duas inspirações centrais: a dimensão espacial do fenômeno turístico (lugares) e multiplicidade de interpretações para a ideia de mobilidades (em movimento) - não apenas restrita ao movimento de corpos, mas pensando os cinco tipos de movimentos propostos por Sheller e Urry (2006), a saber: de corpos, de objetos, imagens virtuais e mensagens.

Assim, a noção de mobilidades turísticas pressupõe que a produção de lugares turísticos está condicionada ao fluxo de turistas, mas não apenas. Há uma série de outros fluxos que concorrem para a produção das mobilidades turísticas, como os investimentos de redes hoteleiras internacionais e companhias aéreas, a movimentação de ingredientes e dejetos (do setor de cruzeiros, por exemplo), a movimentação da força de trabalho em diferentes escalas (intra-urbana e global), dentre muitos outros. Tais fluxos também provocam uma aproximação metafórica aos lugares em si, ou seja, os lugares também se movem. Eles se movem através das fotografias dos turistas, da literatura, do cinema, mas também 
dos objetos como os souvenires. Em estando os lugares em movimento, difundem-se modelos, ideias, concepções de uma cultura turística em constante deslocamento e (re)produção. Apesar de sabermos que há uma vasta e antiga teorização sobre o conceito de lugar - especialmente na geografia, nos estudos urbanos, na sociologia, e outras áreas do conhecimento -, optamos por uma aproximação livre ao termo, mais ou menos como na acepção original do texto.

Além de traduzir o capítulo inicial, buscamos atualizar e expandir algumas análises, tendo uma de suas autoras como coautora deste texto - tanto porque é uma das vozes mais relevantes nos estudos de mobilidade pela vertente que se apresenta, quanto porque traz outros aportes para a discussão sobre turismo com o benefício de um olhar interno (das mobilidades) e externo (ao turismo). Aqui, por suposto, não se pretende produzir uma análise bibliométrica de tudo o que se produziu sobre turismo e mobilidades - ou, ainda mais especificamente, mobilidades turísticas - tampouco construir um tratado definitivo sobre o tema, que, como argumentamos, ainda está em construção há cerca de 20 anos. Ao contrário, o que esperamos é apresentar algumas boas chaves de leitura, para que a distância entre turismo e mobilidades - que na prática é virtualmente nenhuma - ganhe agendas de pesquisa de maneira mais recorrente, séria e inovadora.

\section{SOBRE LUGARES, TURISMO E MOBILIDADES}

Os estudos sobre as mobilidades turísticas partem do princípio que os lugares turísticos se organizam através de uma constante elaboração: feitos e refeitos pelas mobilidades e performances de turistas e trabalhadores, imagens e patrimônio, as últimas modas e as mais recentes doenças. 0 lúdico ou o potencial de um lugar para a fruição turística refere-se, em parte, à vontade de viajar para outro lugar, o prazer de mergulhar noutro ambiente e o fascínio por pequenas diferenças na materialidade do mundo.

Mas o que provoca esse fascínio por outros lugares? O que torna um lugar desejável para se visitar? E mesmo que desejemos esse outro lugar, porque é que nos damos ao trabalho de visitá-lo fisicamente? Quais são os prazeres só disponíveis através da nossa presença física? Por que estar num outro lugar, afinal?

Mas além disso, a diversão proporcionada pelos lugares também diz respeito às maneiras pelas quais os próprios lugares estão sempre em movimento. Os lugares são performados, muitas vezes em uma espécie de palco global, e nessas performances são colocados em disputa com outros lugares, tornando-se mais ou menos desejáveis, mais ou menos visitados.

Os lugares consistem em coisas físicas, que estão sempre em movimento: novos empreendimentos hoteleiros, aeroportos e estradas, praias e vulcões em erupção, mosquitos picando e vírus mortais - sem esquecer que um lugar pode, em sentido figurado, morder de volta. Então também perguntamos: o que precisa ser mobilizado para converter determinado tipo de lugar, como uma praia, uma cidade ou um patrimônio, em turístico? Em que medida lugares são reinventados para atrair e capturar pessoas em movimento - ou aquelas que desejam se movimentar? Se estamos em outro lugar com muitas outras pessoas, qual a 
consequência disso para esses lugares? Como os lugares turísticos são estabilizados e elaborados, e como eles são desfeitos e superados?

Referimo-nos, então, às mobilidades turísticas não apenas para afirmar o óbvio (que o turismo é uma forma de mobilidade), mas para destacar como diferentes e múltiplas mobilidades informam sobre o turismo, moldam os locais onde o turismo é realizado e impulsionam a construção e desconstrução de destinos turísticos. Mobilidades de pessoas e objetos, aviões e malas, plantas e animais, imagens e marcas, sistemas de dados e satélites, todos acabam de algum modo produzindo o turismo. 0 turismo também diz respeito às mobilizações relacionais de memórias e performances, gêneros e corpos racializados, emoções e atmosferas. Os lugares têm múltiplos e contestados significados, que muitas vezes produzem interrupções e disjunções.

Por isso, as mobilidades turísticas envolvem complexas combinações de movimentos e pausas, realidades e fantasias, lazer e trabalho. Neste artigo, começamos descrevendo brevemente as mobilidades turísticas contemporâneas, que cada vez mais constituem relações globais - mas com óbvias ramificações locais nem sempre reconhecidas. Em seguida, discutimos os lugares turísticos e como esses lugares se movem. Uma abordagem que olha para os diversos sistemas que orquestram, organizam e executam esses impulsos de estar em outro lugar e a materialização de lugares que se tornam objeto de desejo.

Apresentamos alguns temas que têm sido desenvolvidos na literatura sobre mobilidades turísticas, tratando de lugares turísticos na América Central e do Sul, Austrália, Índia, Ásia Oriental, Caribe, Mediterrâneo e Atlântico Norte, bem como viagens de volta ao mundo - incluindo algumas menções ao Brasil ${ }^{1}$.

Uma área inicial de trabalho neste campo se concentrou na praia e na ilha como locais privilegiados para o lazer. A iconografia das praias turísticas contemporâneas oscila entre paraíso global, lugares de lazer, nudez, prazer e exibicionismo (Corbin, 1994; Löfgren, 1999). O Caribe, especialmente, passou a significar um lugar com potencial de atração vinculado à sensualidade, que estabelece um padrão para praias do mundo inteiro (Sheller, 2003, 2004a; 2004b); até mesmo para os chamados ecoturistas, cujo desejo de se aproximar da natureza produz novos significados para as areias (Duffy, 2004). Mas existem outras praias marcadas pelo movimento do surfe e não pela fruição estática: ali, surfistas aproveitam o movimento das águas formado pelos tubos de ondas, imagem consagrada e circulada por revistas, filmes e outros imaginários do surfe ao redor do mundo - como no caso clássico do Havaí (Shields, 2004). Há ainda a ascensão e queda dos balneários, dos destinos de praia como Ayia Napa, no Chipre (Sharpley, 2004), onde a vida de ilhas inteiras oscilam ao sabor dos fluxos inconstantes do turismo, e tantos outros pelo mundo, como a costa dos países mediterrâneos e mesmo os clássicos balneários ingleses (Urry, 1990) e reproduções deste modelo em outras latitudes.

Outra área chave da pesquisa em mobilidades turísticas tem se concentrado em performances do patrimônio global, explorando como o patrimônio é mobilizado dentro e através do turismo, formatado e exposto em museus, sítios do patrimônio mundial e lugares históricos. A invenção da tradição, do patrimônio e

1. Os trabalhos que compõem o livro foram citados no texto original e aqui mencionados na forma de referência completa. Assim, mantê-los no texto foi uma opção para que se tenha melhor noção sobre a obra como um todo, ao mesmo tempo que se busca maior fidedignidade à sua estrutura original. 
da memória cultural tem sempre efeitos reais: reinventando um lugar, frequentemente através de requalificações urbanas, onde áreas inteiras são reconstruídas, reestruturadas e renomeadas, muitas vezes como patrimônio. Fluxos globais de capitais e turismo se direcionam para lugares, transformando-os, mas também sujeitando-os a uma glocalização e temporalidades divergentes (Cuthill, 2004; Arellano, 2004; Edensor, 2004). E nos museus, culturas e corpos são exibidos à medida em que as conexões transnacionais são feitas e desfeitas, e as distinções (de classe, gênero e habitus) trabalhadas e retrabalhadas no tempo e do espaço (Bærenholdt \& Haldrup, 2004; Lai, 2004).

Além disso, as mobilidades turísticas são estudadas em função da invenção e reinvenção de lugares turísticos, bem como de seu declínio e esquecimento. As cidades globais são reinventadas como locais-chave a partir de onde se desencadeiam as mobilidades associadas do turismo. Algumas cidades como Hong Kong e Barcelona passaram por contundentes remodelações urbanísticas para se apresentarem como atrações num palco global altamente competitivo de destinos de classe mundial (Sum \& So, 2004; Degen, 2004).

Mas o turismo também ocorre em outras paisagens urbanas mais desvalorizadas, como os subúrbios da pobreza europeia (Halgreen, 2004) e as favelas do Rio de Janeiro (Jaguaribe \& Hetherington, 2004; Freire-Medeiros, 2009, 2013). Consideradas lugares de perigo e encantamento, monotonia e deslumbramento, as favelas tornaram-se os novos lugares para visitação no início dos anos 2000 e passaram a figurar entre os principais atrativos oficiais da cidade do Rio de Janeiro no contexto dos megaeventos (Moraes, 2016, 2017). Procurados, majoritariamente, por uma classe média pós-moderna fascinada e repelida pelo seu urbanismo pós-apocalíptico indescritível, indistinto.

Novos tipos de lugares turísticos também desafiam as fronteiras convencionais dos estudos de turismo, voltando atenções das mobilidades turísticas para lugares inesperados: pessoas que documentam as suas viagens globais para quem ficou em casa através blogs, sites e mais recentemente Facebook e Instagram (Germann-Molz 2004), plataformas, ilhas e outros lugares artificiais (Junemo, 2004), locais que passaram por desastres nucleares (Sullivan, 2004) e locais de risco, sofrimento e morte (Urry, 2004).

0 próprio significado do lugar está em jogo, em exposição ou à disposição em um mundo de riscos, simulações, doenças sempre mutantes e terrorismo. Em última análise, nem todos os jogos são divertidos: os lugares turísticos são também frequentemente lugares de doença, perigo e morte, especialmente porque o mundo é atualmente assombrado pelo terrorismo global, pela perturbação provocada pelo próprio turismo, pelas mazelas sociais estruturais (que muitas vezes coexistem lado a lado com processos de turistificação) e, mais recentemente, por um pandemia causada pela COVID-19 - que, aliás, não é a primeira e provavelmente não será a última. Já não sabemos mais se o turismo irá se recuperar nas suas formas anteriores - e tampouco se isso é algo a ser desejado.

0 turismo, em si, também está em movimento, tornando-se menos previsível à medida que as noções de lazer, autenticidade e risco transformam radicalmente as mobilidades globais. Turismo e viagens compõem o maior setor econômico do mundo, representando 10,3\% do PIB mundial, 6,8\% das receitas mundiais de exportação e 10\% do emprego no mundo (World Travel and Tourism Council, n.d). Quase todo país é, em alguma medida, emissor ou receptor de visitantes. 
Em nível internacional, há mais de 1,4 bilhões de passageiros legais por ano (contra 25 milhões em 1950) e mais de 13 milhões de passageiros aéreos por dia (International Air Transport Association, 2020); 2,7 milhões de passageiros voam nos céus dos Estados Unidos diariamente (Federal Aviation Administration, 2020), o equivalente a uma grande cidade; metade dos adultos britânicos voaram durante 2001; em nível mundial, há um carro para cada 7 pessoas, prevendo-se que as viagens de automóvel tripliquem entre 1990 e 2030. Esta mobilidade é altamente significativa para o meio ambiente em escala global, representando um terço do total das emissões de $\mathrm{CO}_{2}$ (Urry, 2003a) e contribuindo para a elevação do nível do mar, que já ameaça submergir muitos dos atuais lugares turísticos.

Na década de 1990, assistiu-se a uma notável compressão do espaço-tempo. Pessoas de todo o mundo foram aproximadas através de tecnologias variadas - ainda que obviamente este processo ocorra de maneira altamente desigual. Houve e ainda há uma aparente morte da distância no que é por vezes descrito como uma modernidade líquida fluida e acelerada, segundo Bauman (2000), em grande medida pela generalização das comunicações digitais. Basta lembrar que são mais de 4,6 bilhões de usuários de internet em todo o mundo; no Brasil, em 2017, eram cerca de 126,3 milhões (Internet World Stats, n.d; IBGE, 2018).

Mas esta compressão do espaço-tempo decorre também dos rápidos fluxos de viajantes, migrantes e turistas que se deslocam fisicamente de um lugar para outro. A escala dos deslocamentos físicos é imensa, o maior movimento pacífico de pessoas através das fronteiras nacionais. Quase todas as sociedades do mundo são transformadas por fluxos de turistas, uma vez que paulatinamente mais lugares são inventados e reinventados turisticamente para receber esses fluxos. Isto não quer dizer que tais fluxos sejam livres, incontidos ou aleatórios; há fronteiras, polícias e seguranças que filtram os turistas legítimos, com os seus vistos turísticos, e separam-nos dos quase 80 milhões de deslocados forçados, cuja chegada e fixação em novos lugares é frequentemente contestada (ver United Nations High Commission for Refugees, n.d). Estes casos ilustram as categorias metafóricas de "turistas" e "vagadundos", indicando que o nível de controle sobre seus movimentos varia entre grupos sociais distintos (Bauman, 2000).

Essas mobilidades globais pressupõem o crescimento de uma reflexividade turística, um sistema de governança que garante que um número crescente de lugares em todo o mundo monitore, avalie e desenvolva seu potencial turístico. Esta reflexividade envolve identificação e localização de um lugar e seus contornos da geográficos, históricos e culturais que giram ao redor do globo, e a localização de seus recursos materiais e semióticos reais e potenciais. Um bom exemplo disso é o estranho legado de Havana, com seus carros americanos dos anos 50 e sua capacidade metonímicadesignificaroimperialismoculturalamericanodosanos 50 em seuapogeu pré-comunista. Ou ainda, as favelas turísticas do Rio de Janeiro, que se re-inventam turisticamente e se vendem e são vendidas como uma metonímia de Rio de Janeiro, ou de um Rio de verdade, ou mais, como metonímia de Brasil, representando assim, a realidade brasileira (Jaguaribe \& Hetherington, 2004; Freire-Medeiros, 2013).

Essa reflexividade envolve redes de procedimentos sistemáticos, regularizados e de avaliação que monitoram, modificam e maximizam a localização de cada lugar dentro de uma turbulenta ordem global. Tais redes inventam, produzem, comercializam e circulam, especialmente através da TV global e da Internet, lugares e seus significados, redesenhando-os (e re-redesenhando-os). 
No Brasil, essa reflexividade do turismo envolve, ainda, a institucionalização dos estudos de turismo (desde a década de 1970), bem como a criação de empresas de consultoria contratadas por governos municipais, estaduais, nacionais e órgãos internacionais, associações voluntárias e ONGs. Com o maior protagonismo de algumas comunidades nos processos de planejamento e gestão do turismo (especialmente no turismo de base comunitária), organizações comunitárias ganharam alguma visibilidade - ainda que nem sempre com a necessária representatividade nos processos decisórios. Em suma, é inquestionável que o turismo como objeto de reflexão e mecanismo de desenvolvimento tenha ganho mais centralidade nas pautas nacionais.

Ao que parece, quase todos os lugares podem ser reinventados para o turismo, até mesmo lugares como Las Vegas, que no passado teve uma colocação relativamente consolidada no palco global (ver Rothman, 2002). E novos centros globais muito parecidos entraram para a lista dos destinos nos últimos 20 anos por exemplo, Macau (China), Dubai, Abu Dhabi (Emirados Árabes Unidos), ou até mesmo locais em países bastante fechados até recentemente, como a nova capital do Cazaquistão, Astana - ainda desconectada de fluxos globais, mas com intenções não menos extravagantes.

De fato, de modo mais geral, há uma gama incrível de empregos no turismo global. A maioria das pessoas em todo o mundo não pode deixar de ser implicada ou afetada por estes circuitos de turismo e viagens. Tais empregos incluem agências de viagem; transporte; hospitalidade (especialmente na hotelaria); bares, clubes, restaurantes e cafés; arquitetura, design e consultorias; mídia para divulgar imagens através da imprensa, TV, notícias e internet; eventos artísticos e esportivos e festivais; e campanhas de ONGs a favor ou contra o desenvolvimento turístico - seja para conter o avanço do turismo em áreas naturais frágeis, ou para barrar os incessantes fluxos em destinos consagrados.

0 crescimento do turismo também acaba sendo responsável por reformular mais amplamente os padrões de urbanização, de desenvolvimento de infraestrutura (estradas, aeroportos, portos), de agricultura e importação de alimentos, de produção artística e cultural, com implicações para quase todos os setores econômicos. Algumas cidades emblemáticas conjugam a visão do século XXI, como mostrado na recente reformulação de Las Vegas como um centro de entretenimento familiar (Rothmann, 2002). Ou ainda como o Rio de Janeiro, que se reinventa como cidade inteligente, cidade sustentável, cidade segura, para citar algumas das re-invenções do Rio no contexto de cidade sede dos megaeventos (ver Menezes, 2015; Moraes, 2017, Freitas, 2018).

Se o turismo está transformando fisicamente muitos lugares reais, ele também está impactando profundamente a criação de realidades virtuais e lugares fantasiados. Cada vez mais marcas ou logotipos globais poderosos e onipresentes põem em destaque locais/visões turísticas como componentes-chave da cultura global que sua marca reforça, e com a qual dialoga. As empresas nas últimas décadas passaram da fabricação de produtos para a produção de marcas, envolvendo enormes despesas de marketing, design, patrocínio, relações públicas e publicidade. Estas empresas de marcas incluem muitas em no setor de viagens e lazer: Disney, Hilton, Nike, Gap, Easyjet, Body Shop, Virgin, Club Med, Starbucks, Coca Cola, e assim por diante. Estas marcas produzem conceitos ou estilos de vida: liberadas da carga do mundo real das lojas e da fabricação de produtos, 
elas marcas são livres para voar, menos como a disseminação de bens e serviços do que como alucinações coletivas (Klein, 2000, p. 22).

Estes conceitos de estilo de vida giram em torno de tipos genéricos de lugares para diversão: a piscina do hotel, o café/restaurante à beira-mar, a cidade cosmopolita, o buffet do hotel, o parque temático, o coquetel, o clube, o lounge do aeroporto, o bronzeado, a dança exótica e a praia global (ver Löfgren, 1999, no último; e Rothman, 2002, sobre o papel da Coca-Cola na substituição de Las Vegas).

Lugares virtuais para a diversão também podem ser produzidos do zero (Junemo, 2004), construídos a partir de memórias (Bærenholdt \& Haldrup, 2004), ou construídos na internet (Germann-Molz, 2004). Se o turismo às vezes parece irreal, ele ainda assim mobiliza os corpos em encontros sensuais com o mundo físico. Desafios físicos como surfar (Shields, 2004), caminhar até Machu Picchu (Arellano, 2004), tornar-se um construtor naval ou marinheiro Viking (Bærenholdt \& Haldrup, 2004), ou sobreviver em zonas de risco urbanas permitem ao turista colocar seu próprio corpo em jogo (Halgreen, 2004; Jaguaribe \& Hetherington 2004). Como Löfgren (2004) escreve: "a gramática das experiências paisagísticas inclui todas as diferentes formas turísticas de 'entrar em uma paisagem': atravessá-la, passar por ela ou ultrapassá-la, habitá-la, senti-la, fazer parte dela...as paisagens são produzidas pelo movimento, tanto dos sentidos quanto do corpo (p. 106)".

Os lugares não são simplesmente encontrados: são produzidos pelas performances de corpos, como, por exemplo, os corpos de turistas. Esta performance requer apetrechos como calçados de caminhada e mochilas, câmeras discretas, cintos em que guardamos dinheiro embaixo da roupa (doleiras), trajes de banho e toalhas ou cangas para tomar sol, ou trajes adequados para dançar. Também requer equipamentos nos lugares turísticos: letreiros e passarelas, ferrovias e carros blindados, réplicas do patrimônio histórico e edifícios icônicos pós-modernos. Estas micro-mobilidades são cruciais na encenação do turismo e também para o complexo jogo das mobilidades turísticas na escala global.

Tais mobilidades complexas também envolvem muitos riscos, e parte da reflexividade do turismo é a consciência dos riscos que ele enseja. 0 turismo sempre foi acompanhado de riscos para os indivíduos: doenças, ataques, atenção sexual indesejada, viajar por lugares perigosos onde se pode ser preso, ou de se perder e ser incapaz de se comunicar. Mas hoje existem também outros tipos de riscos, associados a novos e imprevisíveis surtos de doenças como a SARS (Sum \& So, 2004) ou mais recentemente a COVID-19, que mostram uma mobilidade excepcional ao passar de pessoa para pessoa. Há ainda, ataques terroristas chocantes em destinos turísticos de primeira linha (Urry, 2004), ou num sentido mais mundano os riscos de mover coleções de arte inestimáveis para exposições internacionais (Lai, 2004) ou de escolher ser um turista em lugares perigosos ou de risco (Sheller, 2004a, 2004b; Hallgren, 2004; Jaguaribe \& Hetherington, 2004). Os próprios riscos são móveis, como o da radiação nuclear (Sullivan, 2004), e as mobilidades do turismo geram muitos novos riscos que resultam em mais vigilância. Há, portanto, um grande número de pessoas e lugares que se enredam neste turbilhão de sistemas de mobilidades turísticas.

Não existem duas entidades separadas, turismo e mobilidades, como se houvesse apenas uma conexão externa de uma coisa com a outra. Turismo e mobilidades são, na realidade, parte e parcela do mesmo conjunto de sistemas complexos e 
interconectados, cada um produzindo o outro. Neste sentido, são muitos discursos, formas e corporificações de lugares turísticos e performances turísticas.

As mobilidades turísticas contribuem para a produção de espaços mais e menos ordenados, usando padrões genéricos para moldar espaços com certos tipos de recursos (Edensor, 2004), e esses ordenamentos agora são encontrados em praticamente todas as partes - seja na materialidade e nas rotinas de visitação dos lugares turísticos, ou nos elementos, sensações e imaginários turísticos dos muitos agentes ligados (ou potencialmente ligados) ao turismo.

De certa forma, ainda que pareça um contrassenso, poderíamos dizer que há menos turismo presente de maneira característica no tempo-espaço; com efeito, na medida em que a estar em casa e o fora de casa ficam cada vez mais semelhantes, podemos, metafórica e ironicamente, estar diante do fim do turismo (Gale, 2009; Germann-Molz, 2004; Hannam, 2009) no marco de uma economia de signos. Ao mesmo tempo em que os lugares turísticos se proliferam por todo o mundo, os lugares do cotidiano são ressignificados no modo turístico, por exemplo, na tematização dos ambientes de compra, lazer e trabalho. Esse fenômeno foi chamado de de-diferenciação do turismo (Lash \& Urry, 1993), sendo aplicado na forma de políticas urbanas e territoriais de forma muito inteligente. Basta olhar, por exemplo, o lema da AirBnB ("viver como um local") que promete um turismo recoberto de uma suposta autenticidade do cotidiano. $\mathrm{Ou}$, ainda, o que se projeta nas tendências do turismo de proximidade, slow tourism e staycation nos cenários pós-pandemia da COVID-19 para o turismo - apesar de estas práticas já serem objeto de estudo há mais de 10 anos (Germann-Molz, 2009; Soría \& Coit, 2013).

De maneira figurada, podemos dizer que Mickey Mouse escapou de seu reino especial e agora parece ocupar quase todos os lugares do mundo - afinal, há um número extraordinário de lugares globais onde Mickey pode fazer suas estripulias. Como então analisar e entender esses lugares?

\section{LUGARES TURÍsticos (PLACES TO PLAY)}

Em geral, parte-se do princípio de que há turistas ou turistas potenciais de um lado, e lugares que se constituem em destinos turísticos potenciais, do outro. Pesquisadores de turismo costumam estudar as forças que impulsionam turistas individuais ou grupos de turistas a viajar para um ou outro destino. Já psicólogos e economistas normalmente veem os fatores que induzem tais viagens como indivíduos, enquanto sociólogos ou antropólogos procuram por mais fatores sociais. Mas em qualquer caso costuma-se acreditar numa ontologia de eventos separados, onde se presume que os lugares e culturas são relativamente fixos e dados, e que isso empurra ou puxa turistas, de tempos em tempos, de um lugar para outro (ver críticas em Coleman \& Crang 2002a, p. 11; Minca \& Oakes 2004a e b).

A ideia subjacente aqui, por outro lado, é que as atividades turísticas não são tão separadas dos lugares que são visitados. E mais, esses lugares não são fixos e imutáveis, mas dependem em parte do que acontece dentro deles. Além disso, devemos considerar as muitas sobreposições entre o turismo e outros tipos de negócios, fluxos profissionais e migratórios, incluindo os negócios associados à cultura e ao patrimônio (Cuthill, 2004; Bærenholdt \& Haldrup, 2004; Lai, 2004), 
aos esportes (Shields, 2004; Degen, 2004) e até mesmo à geração de energia nuclear (Sullivan, 2004).

Por isso, é preciso consolidar a ideia de que o turismo não é uma atividade de lazer pura realizada apenas dentro do reino do Mickey Mouse. E os lugares turísticos envolvem apresentações de vários tipos de anfitriões e especialmente de convidados. Isto faria sentido quando pensamos nesta ontologia de eventos separados, mas muda um pouco quando fazemos uma análise de diversas mobilidades que se cruzam a partir dos sistemas complexos. Estes sistemas envolvem redes de anfitriões-convidados-tempo-espaço-culturas que estabilizam certos lugares como lugares turísticos, mas de forma controlada.

Neste sentido, as mobilidades turísticas são um manifesto pela descentralização dos estudos do turismo, afastando-os dos turistas e aproximando-os das redes ou sistemas que produzem e reproduzem lugares turísticos. Assim, os lugares devem ser vistos como resultados econômicos, políticos e culturais das múltiplas redes de mobilidades de capitais, pessoas, objetos, signos e informações (especialmente através de vários meios de comunicação globalizados). Tais mobilidades se movem em velocidade rápida, porém desigual, atravessando muitas (ou sendo barrados em) fronteiras.

Os lugares não são fixos ou dados, eles estão mesmo em jogo em relação às múltiplas mobilidades (Rojek \& Urry, 1997; Ringer, 1998; Coleman \& Crang, 2002b). Os lugares são assim dinâmicos, são eles mesmos lugares de movimento (Hetherington, 1997), como navios movimentando-se e não necessariamente estáticos em um único local. Eles viajam, lenta ou rapidamente, distâncias maiores ou menores, dentro de redes de agentes humanos e não-humanos. Neste sentido, a noção de lugares se estrutura em função dos posicionamentos de pessoas, materiais, imagens e sistemas de diferença por eles produzidos. Em particular, os lugares estão localizados em relação aos ambientes e objetos materiais, assim como os significados e interações humanas (Coleman \& Crang 2002a, p. 11).

Diversos estudos examinam o papel dos objetos na fixação de redes de prazer e diversão: pranchas de surfe em Bondi e seu posterior desenvolvimento através de tecnologias militares (Shields, 2004), água mineral, chás e cafés em Harrogate (Cuthill, 2004), restos de barcos Viking encontrados no fiorde de Roskilde (Bærenholdt \& Haldrup, 2004), objetos de arte e pinturas em vários museus e galerias no Leste e no Oeste (Lai, 2004), enormes ilhas artificiais sendo construídas em Dubai em uma escala tal que sua forma cuidadosamente projetada só é visível do ar ou do espaço (Junemo, 2004), e radiação nuclear invisível em locais turísticos radioativos (Sullivan, 2004). Mais recentemente, foi demonstrado como as formas de comer e beber relacionam-se de maneira complexa com o ambiente físico em que são realizadas - como já discutido sob a égide da estetização (Featherstone, 1991; Lipovetsky \& Serroy, 2015). Com a proliferação de múltiplas possibilidades de turismo gastronômico (Hall et al., 2003), existem muitas arquiteturas do comer" (Horwitz \& Singley, 2004).

0 que os sistemas de mobilidades fazem é apenas fixar os lugares adequados para a fruição e as diversões de todo tipo (ver Judd e Fainstein, 1999 para uma economia política de lugares). Novos lugares baseados em novas performances estão sempre próximos, emergindo do turbilhão dos processos econômicos, sociais e culturais. Estes processos circulam, mudando a posição dos lugares e pondo em movimento outros novos e inesperados, como o quase inacessível 
Machu Picchu, nos Andes peruanos (Arellano, 2004), enquanto outros rapidamente saem de cena, a exemplo de destinos litorâneos no Chipre (Sharpley, 2004).

0 status de lugar em si entra em questão, uma vez os lugares reais e virtuais são intercalados uns com os outros. Como podemos entrar em uma cidade que, na linguagem coloquial é identificada como "não está no mapa"? Como no caso das favelas e outras comunidades periféricas normalmente entendidas como ocupações irregulares (Jaguaribe \& Hetherington, 2004)? Um site que apresenta o mundo todo digitalmente pode ser considerado um lugar global (Germann-Molz, 2004)? Que tipo de lugar turístico é um reator nuclear ou um lugar imaginário comemorativo do holocausto nuclear (Sullivan, 2004)? Estas possibilidades derivam, em parte, de como os lugares turísticos requerem e pressupõem performances de anfitriões e visitantes (ver Coleman \& Crang, 2002b).

Não se trata apenas de uma questão de qualidade de serviços ou atendimento ao cliente, mas de uma complexa relação entre visitantes, visitados e suas performances ou comportamentos possíveis e até lucráveis. Zukin (2003) examinou certas complexidades em tais desempenhos, analisando a compra potencial de um jarro. Uma pessoa em Manhattan, pode performar uma flâneur em uma área de lojas que vendem artesanato europeu importado de alta qualidade; ela consome visualmente um estilo particular de jarro. Na Toscana, ela encontra dezenas destes mesmos jarros em uma versão turística, enquanto se apresenta como consumidora turística. Mais tarde, ela acumula experiência neste estilo de jarro e desenvolve performances de quem é uma conhecedora do assunto, desfrutando da emoção da viagem, da busca e da aquisição. E finalmente, quando ela viaja para o site de compras eBay, ela se torna uma compradora e vendedora comercial desses jarros. Assim, a tarefa aparentemente simples de comprar um jarro pode ser realizada de maneiras impressionantemente diferentes, desde um flanar até uma viagem comercial virtual, passando pelo consumismo turístico e o espírito empresarial. Da mesma forma, tanto os anfitriões quanto os visitantes estão envolvidos em múltiplas performances à medida que seus corpos se movimentam entre locais de moradias, salas de espera de aeroportos, praias, bares, restaurantes, cidades ou museus, e à medida que se comunicam uns com os outros através de gestos, textos escritos, tradutores, telefones, conexões de internet e máquinas de cartões de crédito.

Essas performances corporais envolvem simplificações substanciais das trocas e contatos culturais, especialmente quando são tratados como commodities. É possível observar como isso ocorre com antigas culturas Inca e Viking consumidas no padrão Disney (Arellano, 2004; Bærenholdt \& Haldrup, 2004) ou nos encontros entre classes ocorridos no turismo de setores da classe médias em países em desenvolvimento (Sheller, 2004a, 2004b; Edensor, 2004; Jaguaribe \& Hetherington, 2004). MacCannell explora estas complexas relações em viagens canibais em partes de Papua Nova Guiné (1992; e ver Smith, 1989). 0 desenvolvimento do turismo em favelas mostra algo semelhante, pois o verdadeiro Rio é autenticamente encenado para visitantes como se estivessem em um safári (Jaguaribe \& Hetherington 2004). E o distanciamento entre turistas e anfitriões é naturalizado como um aspecto da cultura local, no qual encontros são cuidadosamente encenados em ambientes controlados (Sheller, 2004a, 2004b; Edensor, 2004).

Os lugares são assim criados através de sistemas organizados e/ou informais de performances de turistas e anfitriões. As performances dos turistas incluem 
flanar, escalar, coletar, relembrar, passear, comprar, conversar, beber, tomar banhos de sol, fotografar, ler, dançar, postar fotos e textos em sites e redes sociais, surfar, comer, dirigir, etc. Já as performances dos anfitriões incluem orientar, limpar, cozinhar, servir, dirigir, dançar, tocar música, vender, sorrir, e assim por diante. Mas em muitos casos tais papéis e suas performances são profundamente contestados, especialmente quando as lutas políticas locais interferem nos processos decisórios através dos quais os lugares são reinventados e mobilizados para o turismo, tais como as batalhas pelo acesso ao Taj Mahal, a revitalização de Barcelona (que resultam, recentemente, em ondas de reações ferozes contra turistas), o empacotamento de Hong Kong, ou ainda a euforia em torno do Rio de Janeiro dos megaeventos.

Mas se as performances de turistas e anfitriões deixarem de ocorrer, o lugar turístico também deixará de acontecer como tal. Locais com outras configurações de recursos materiais e semióticos ultrapassam rapidamente lugares que não mais oferecem as performances certas em escalas apropriadas. Isto é demonstrado no caso de Hong Kong, cujo papel central na diáspora chinesa o colocou no olho da tempestade da epidemia da SARS, que levou a uma queda cataclísmica nos visitantes (Sum \& So, 2004). Na medida em que os lugares são construídos como playscapes com revestimentos estéticos (ver Junemo, 2004 para uma discussão sobre os espaços artificiais de Dubai), aqueles que são capazes de se renovar rapidamente serão mais capazes de se manter no jogo.

Os anfitriões são cada vez mais de outros lugares; não são objetos imóveis do olhar do turista, mas muitas vezes são agentes, estando também em movimento. Muitos prestadores de serviços turísticos - especialmente nas grandes cidades estão em movimento, passando por aquele lugar, e não são mais locais do que os visitantes reais. Muitos se mudaram para trabalhar nos setores que prestam serviços de turismo, mas também podem estar empenhados em consumir aquele lugar ao mesmo tempo em que nele trabalham. Vemos isso em Dubai (Junemo, 2004) e especialmente nas paisagens urbanas noturnas de Chipre, Harrogate e Barcelona (Sharplen, 2004; Cuthill, 2004; Degen, 2004; ver também Chatterton $\&$ Hollands 2003). De alguma maneira, isso escancara como um estilo de vida turístico define muito da produção e da circulação dos lugares turísticos na contemporaneidade - a despeito dos condicionantes de origem geográfica de quem viaja e a precisão territorial de sua ocorrência.

\section{LUGARES EM MOVIMENTO (PLACES IN PLAY)}

Os lugares estão situados em diferentes estágios e posições dentro de fluxos globais: há lugares que acompanham o fluxo e aqueles que ficam parados com uma infraestrutura ultrapassada, hotéis que subitamente saem de moda, sistemas de transporte que ficam obsoletos, e assim por diante. Alguns desses lugares se movem para mais perto dos vários centros globais (que também estão neste jogo dos lugares), enquanto outros se afastam ainda mais. A própria constituição de centros globais e lugares periféricos (e a globalização de alguns lugares como lugares globais) é uma função dessas configurações mutáveis de mobilidades e imobilidades.

Novos lugares turísticos estão sempre ali na esquina, ao passo que outros estarão à margem de uma ordem global, como Sellafield em Cumbria, noroeste 
da Inglaterra, assim como outros locais nucleares (Sullivan, 2004), subúrbios parisienses (Halgreen, 2004), o próprio globo terrestre (Germann-Molz, 2004). Praias podem ser deslocadas de um lugar para outro para criar lugares ecoturísticos (Duffy, 2004), e ilhas inteiras são construídas do zero (Junemo, 2004). Outros lugares se afastam ainda mais, como no caso de Chipre após a explosão da bolha de Ayia Napa (Sharpley, 2004) ou Hong Kong após a SARS ter levado à patologização do destino (Sum \& So, 2004).

Essas mobilidades de lugar são altamente voláteis e imprevisíveis. As bombas terroristas podem afastar o turismo de lugares como Luxor no Egito, praia de Kuta em Bali, ou Jerusalém em Israel, mas, por outro lado, lugares de alto risco e morte podem ser transformados em lugares desejáveis para visitar como locais de turismo sombrio - ou dark tourism (Lennon \& Fooley, 2000; Urry, 2004).

De modo mais geral, surge um palco global, abrindo a cortina para novos lugares e experiências. Nesse palco, cidades, ilhas e países aparecem, competem, se mobilizam como espetáculo, desenvolvem sua marca e atraem visitantes, negócios e status. Cada vez mais, bons lugares para visitar são, muitas vezes, bons lugares para trabalhar, como no caso de vários lugares bons para se viver ao longo da costa sul da Califórnia (Nevarez, 2002), bem como Algarve, sul de Portugal. Entretanto, se aqueles que vêm para visitar estão apenas consumindo o lugar como uma paisagem noturna de festas barulhentas, perturbadoras e carnavalescas (como em Harrogate, Cuthill, 2004, ou Barcelona, Degen 2004), então haverá desentendimentos com aqueles que vivem nesses centros urbanos.

Decorrente da saturação e sobre-uso de certas porções da cidades, conflitos ocorrem, por exemplo, entre aqueles que ocupam as paisagens diurnas e as paisagens noturnas dos movimentados centros das cidades - o que vem sendo tratado sob a ideia de overtourism (como o caso dos movimento que pregam Tourists Go Home, em Barcelona, Veneza, Berlim, e outras cidades principalmente europeias). A própria noção de saturação poderia ser considerada uma invenção recente e eurocêntrica - já que, há décadas, destinos tropicais (na Ásia ou no Caribe) sofrem com super-exploração turística e nem por isso debates sobre o tema aparecem na literatura (ou nas comunidades envolvidas). É quando aglomerações tomam Barcelona - ou seja, quando fluxos turísticos e outros semelhantes atingem uma cidade europeia - que o assunto vai ganhar visibilidade (Koens et al., 2018). Este é um exemplo típico de como fluxos e modelos turísticos viajam, bem como se constituem as reações a eles.

Também vemos como a entrada no palco global pode se dar através de megaeventos como os Jogos Olímpicos, Copas do Mundo, grandes exposições de arte internacionais, festivais e Expos. A identidade do lugar depende de sua posição, bem como de seu lugar neste palco global. Tais eventos não podem ser perdidos, produzindo enormes viagens em momentos específicos para pegar o evento ao vivo na hora certa. Eventos globais envolvem momentos de condensação global, com intensa localização de eventos em lugares únicos, uma vez que são palco de eventos únicos. Estes lugares "se transformam de lugares mundanos em lugares especiais por sua condição de 'cidade sede' (Roche, 2000, p. 224)" - ocupando um novo nicho distinto nos fluxos globais.

Barcelona, por exemplo, foi lançada no palco global com os Jogos Olímpicos de 1992 (Degen, 2004) - e, de maneira semelhante, Pequim, em 2008 - e a forma como as exposições de arte itinerantes e internacionais promoveram Taipei, 
a capital de Taiwan, como um lugar capaz de enviar e receber exposições de arte e objetos globalmente importantes (Lai, 2004). Mas também contra-exemplos de campanhas anti-megaeventos - como na Suécia recentemente, ou Rio de Janeiro, no Brasil. A resistência da população sueca à candidatura às Olimpíadas de 2022 abre uma discussão sobre como ser imóvel é um ato de resistência de certas sociedades/grupos. Em outras palavras, não estar no mapa dos megaeventos - e, portanto, não atrair milhares/milhões de visitantes - retrata uma nuance política da imobilidade muito importante. Também movimentos populares contra os megaeventos destacam como ser imóvel (e permanecer, mesmo contra todas as forças institucionais e capitalistas) significa algo no contexto do urbanismo olímpico, bem como a crise política e econômica no Brasil antes, durante e após Rio 2016, indicam o alto custo político, econômico e social dos megaeventos (Nogueira, 2015; Moraes, 2017; Freitas, 2018).

De modo mais geral, o crescimento da internet acelerou o processo de criação e reconstrução de centros globais deste tipo. Dar a volta ao mundo torna-se um evento em si mesmo (ver Germann-Molz, 2004 nos sites round-the-world). Tornar-se um lugar turístico global pode permitir que lugares entrem na ordem global (ou re-entrem, como fez Havana nos anos 90), por exemplo: o marketing de Chipre na esteira de sua divisão militar (Sharpley, 2004); a cidade de Barcelona, negligenciada durante o regime autoritário de Franco (Degen, 2004); o estado petrolífero islâmico de Dubai, que é agora um centro turístico, de compras e entretenimento (Junemo, 2004).

Ademais, houve um grande aumento no número de turistas em muitos países, embora, é claro, as viagens voluntárias ainda sejam esmagadoramente um privilégio daqueles que são, em termos globais, ricos. Mas o Oriente, que já foi visitado e consumido por aqueles do Ocidente, produz cada vez mais visitantes ansiosos para ver com os próprios olhos lugares do Ocidente que parecem ter definido a cultura global, ou pelo menos para importar a cultura ocidental na forma de exposições itinerantes internacionais (Lai, 2004). Hong Kong - e também Cingapura - desempenham um papel fundamental ao proporcionar uma conexão do Oriente com Ocidente, e atrair cada vez mais aos visitantes do resto da China (Sum \& So, 2004). A China, inclusive, entrou no palco dos megaeventos, ao sediar de forma entusiasmada os Jogos Olímpicos de Pequim 2008.

Além disso, os lugares turísticos são lugares de encontro, lugares onde as redes globais se reúnem e socializam. 0 chamado turismo de eventos reinventou Harrogate que passou de uma distinta cidade inglesa a animado destino para congressos e eventos (Cuthill, 2004). Pesquisas geralmente mostram que a sociabilidade urbana é o principal determinante para localização e funcionamento de muitos serviços empresariais (ver as discussões e críticas sobre classes criativas, como em Florida, 2002). Outras pesquisas sobre os setores financeiros de Hong Kong e Cingapura mostram seu uso intensivo de bares, restaurantes, boates, clubes esportivos, festas, eventos patrocinados e associações empresariais (Sum \& So, 2004). "A sociabilidade nestes lugares é a base sobre a qual os contatos e oportunidades são feitos, a confiança e confiabilidade são testadas, o conhecimento e os empregos são trocados, os negócios são testados e selados, a reputação é rastreada e os negócios se tornam mais sociáveis... os locais de prazer na cidade ganham vida como instituições comerciais" (Amin \& Thrift, 2002, p. 75). 
E no turbilhão de processos globais surgem novos lugares para cada geração. As performances turísticas, com efeito, parecem cada vez mais específicas de acordo com cada geração. Assim, muitos desses lugares turísticos globais são extremamente complexos, onde não há uma única experiência. A governança de tais lugares é extremamente complicada, em parte devido à diversidade dos fluxos de pessoas como turistas, migrantes e trabalhadores, tanto do mundo desenvolvido quanto do mundo em desenvolvimento. E também é complexa a diversidade de performances de diferentes idades, classes, gêneros, raças e etnias, que ocorrem, muitas vezes, dentro do mesmo espaço altamente localizado, como vemos nos casos muito conhecidos do Caribe (Sheller, 2004a, 2004b) e do Taj Mahal (Edensor, 2004; 1998).

Os lugares turísticos, portanto, frequentemente conformam um assunto sério para governos, corporações, comunidades, migrantes e ONGs, uma vez que fazem parte de um jogo sem fim de múltiplas mobilidades, entrecruzadas e imprevisíveis. Como se fosse apenas uma escalada de infinito mover-se. Mas há fricções, quase sempre orgânicas, mas às vezes, violentas.

\section{QUAL FUTURO PARA AS MOBILIDADES TURÍSTICAS?}

O ano de 2020 foi sacudido por uma pandemia causada pelo novo coronavírus (SARS-CoV-2), cuja dispersão, em grande medida, foi acelerada pela frenética mobilidade global - aí incluídos desde ávidos turistas de pacote a sôfregos imigrantes sem documentação. Conforme a nova virose se espalhou, o mundo assistiu, como nunca, uma drástica diminuição da circulação de pessoas (de interrupção de conexões aéreas intercontinentais a proibições de acesso a praias e restaurantes).

Esse cenário gerou uma crise de mobilidade, ironicamente em um momento da humanidade em que meios tecnológicos, estruturas cada vez mais complexas e modos de vida desejosos de mais mobilidade sustentavam a dispersão de uma cultura turística quase banal. No campo daquela reflexividade turística, de um lado, grupos e indivíduos trabalham pela recuperação do turismo, com entendimentos de que este cenário é reversível e ajustável, a depender de como novos protocolos sanitários e de viagem sejam implementados; de outro lado, múltiplas questões são colocadas sobre como será o universo das viagens (turismo incluído), inclusive se, após colossal retração, os padrões anteriores poderiam (ou mesmo deveriam) ser restabelecidos - seja por medo, mudança de mentalidade ou novas exigências (sanitárias, econômicas, comunitárias, etc.), abrindo espaço para uma possível reforma do turismo (Brouder et al., 2020; Cave \& Dredge, 2020; Gössling et al., 2020; Lew et al., 2020; Tsionas, 2020).

Contudo, essas e outras questões - por mais que aparentemente muito novas - já são conhecidas nas agendas de pesquisa sobre mobilidades turísticas, uma vez que, como argumentado, não se trata apenas de entender mecanicamente os fluxos que definem o turismo, senão incorporar elementos de natureza variada para a compreensão de um fenômeno multidimensional, intrincado, contraditório e multi-escalar.

Desde a passagem do século XX para o XXI, uma quantidade relevante de publicações vêm buscando conectar os pontos entre turismo e mobilidades (Coles et al., 2005; Hall, 2004; Hannam et al., 2014; Cohen \& Cohen, 2015; Hall, 2015; Coles, 2015; Allis, 2016; Harrison, 2017; Moraes, 2017), ao mesmo tempo em 
que esta se insinuava como um novo paradigma de pensamento no âmbito das ciências sociais. Na medida em que o conhecimento sobre as mobilidades avança, pode-se notar um crescente interesse nas mobilidades turísticas por várias perspectivas, especialmente mas não apenas no eixo Europa-EUA - ver, por exemplo, Allis (2018) para uma análise sobre o contexto latino-americano.

Se esta pandemia escancarou as mobilidades como elementos centrais da vida contemporânea (em suas várias dimensões, inclusive no seu avesso), como já preconizava Urry (2000) desde o início do milênio, há que se ter em vista que, no que diz respeito ao turismo, a imposição de um caminho de recuperação (recovery) sobre uma vertente reformista (reform) poderá escamotear pautas importantes, que transcendem - ou até explicam - este cenário pandêmico.

A ainda sutil - mas inegável - agenda ambiental no turismo não deveria ser ofuscada pela comoção imposta pela pandemia. Da mesma forma, os movimentos de resistência ou legitimação de grupos sociais afetados pelo ou alijados do turismo, que ganharam mais relevância em muitos quadrantes do mundo, não deveriam ser negligenciados em favor de discursos e projetos totalizantes. Por exemplo, se trabalhos anteriores de Sheller focavam na invenção, circulação e consumo dessas ilhas inventadas tanto como assemblage material, quanto como representações culturais (Sheller, 2003a; Sheller, 2004a, 2004b e outros), seus trabalhos mais recentes voltam-se agora os futuros insulares do Caribe, incluindo problemas com o turismo de desastre e uma crítica ao volunturismo humanitário pelas lentes da mobilidade justa (Sheller, 2020a). Na esteira desta pandemia, a autora defende a reconstrução do turismo através de práticas agroecológicas e transições justas que incluam, inclusive, limite às mobilidades de turistas (Sheller, 2020b).

0 aquecimento global é um fato, com consequências naturais, econômicas e sociais assimetricamente distribuídas - inclusive no que diz respeito à produção dos lugares turísticos. Todavia, ironicamente, os níveis de sucesso do turismo em geral dizem respeito a volume de visitantes, entrada de divisas, número de unidades nos negócios turísticos (UHs, leitos, assentos, pagantes, etc.). E de maneira muito colateral se atacam problemas de acesso e distribuição aos recursos para a elaboração ou fruição do turismo. Portanto, uma análise responsável das mobilidades injustas deveria ser a base para reformar o turismo.

John Urry, que projetou um imenso arco teórico entre os estudos de turismo e mobilidades (com relevante aporte das ciências sociais), questionou-se sobre qual seria o futuro das cidades e, de maneira indireta, do mundo urbano e da civilização, que certamente atingem o turismo (Urry, 2016). Ele sugeria quatro categorias de cidades no futuro - o que ajuda inclusive a pensar qual seriam os futuros possíveis das mobilidades turísticas: a fast mobility city (cidade de rápida mobilidade), digital city (cidade digital ou virtual), fortress city (cidade fortificada) e liveable cities (cidades sustentáveis) (Moraes, 2017; 2018).

0 contexto de pandemia, com distanciamento social e muitas restrições em termos de deslocamentos, nos faz pensar logo nos cenários que Urry desenhou para a cidade digital e a cidade fortificada. A primeira seria o contexto onde o movimento físico de pessoas e objetos seria substituído por meios de comunicação e experiências digitais, mais baratos, rápidos, e até mais sustentáveis, além de menos arriscados e supostamente menos restritos, como já haviam observado Elliot e Urry (2010). 
Os lugares digitais seriam palco das performances virtuais de turistas, guias e anfitriões, com lives de roteiros turísticos dividindo a atenção de turistas virtuais com roteiros em realidades virtual e vídeos em 360 graus. De fato, há bastante tempo já se discute e praticam atividades turísticas mediadas tecnologias da informação e comunicação cada vez mais diversas (Gretzel, 2010). Agora, porém, este tema sai da periferia dos debates e ganha mais centralidade no desenho de possíveis cenários para futuros do turismo, provavelmente cercados de maiores restrições à circulação e aos encontros.

Complementando esses lugares virtuais, estariam os lugares fortificados, onde a mobilidade física de corpos e objetos seria bem mais restrita e protegida, com entrada submetida a quarentenas, seguros de saúde rigorosos, pulseiras para controle de localização e temperaturas. Fora dos enclaves, viveriam os mais pobres, os excluídos, que poderiam transitar nas zonas de risco - em alguma medida, uma versão atualizada dos vagabundos de Bauman (2000). Mas também devemos considerar a possibilidade de outras normalidades e outros padrões de consumo mais sustentáveis, ecológicos, lentos e próximos, com menos deslocamentos.

Aqui, contudo, a ideia de mobilidade como desejo absoluto se inverte: quando a circulação implica riscos, a vida reclusa exige - para grupos privilegiados um intricado sistema de fornecimento de mercadorias, comida, informação e imagens (via infraestrutura e tecnologias da informação). Não significa, porém que as hordas de seres móveis (entregadores, trabalhadores de serviços essenciais, e outros que estão a servir os que se beneficiam do privilégio do isolamento) se aproximem minimamente do universo do turismo - nem fisicamente, nem virtualmente. São, como antes (ou até pior que antes), trabalhadores precarizados, com possibilidades ainda mais limitadas para fruir de qualquer forma de turismo - ainda que, ironicamente, relativamente mais móveis do que os grupos a que servem. Ou seja, seguem sendo vabagundos, ainda que servindo a turistas mais estáticos - pelo menos, momentaneamente. Outra ironia!

Os lugares ecológicos ou sustentáveis poderiam ser a mais nova opção de mais novos lugares criados para um novo turismo com menores índices de emissão de carbono e mais qualidade de vida - pondo em destaque a ideia de turismo de proximidade ou mesmo staycation, já pautadas há pelo menos 10 anos quando se faz a crítica sobre a excessiva mobilidade turística (especialmente a partir da realidade do mundo rico do norte). Nesta vertente, espera-se, por lógica econômica, o encarecimento das práticas turísticas convencionais, uma vez que protocolos e exigências sanitárias tornariam a mecânica das viagens bastante mais complicada e custosa.

Ou ainda, podemos voltar para um normal bem parecido com o de antes, a rápida e densa mobilidade continuaria em expansão após uma vacinação em massa, retomaríamos a reinvenção lugares turísticos para receber novos turistas, onde as pessoas continuariam a se mover em larga escala e intensidade da globalização; sem grandes limites no movimento de cidadãos e, especialmente, turistas, onde o status social continuaria a ser ditado também pela viagem e consumo. Esse cenário entusiasmado - embalado pela Organização Mundial do Turismo, por exemplo - depende largamente do sucesso de vacinas, que permitam controlar, por antecipação, contaminações em larga escala, e os impactos brutais de novas pandemias. Cenário bastante incerto, a propósito.

Se o frenesi de mobilidades (inclusive as turísticas) vêm escalando desde meados do século XX, agora, talvez estejamos vivendo a primeira grande retração, 
não por consciência, senão por imposição (parcialmente comparável ao que se viveu após os atentados de 2001, nos EUA). E é diante dela que dois campos argumentativos se constroem, colocando em polos opostos argumentos e providências de recuperação e de reforma - em que, claramente, a primeira tende a se impor, enquanto o sistema de produção capitalista, largamente baseado na economia do petróleo, se sustentar.

Todos esses cenários podem parecer factíveis ou fruto de mera elucubração. Mas a verdade é que todos podem se concretizar em parte, juntos ou misturados. Para a Organização Mundial do Turismo (OMT) - que, desde o início da pandemia vem defendendo a reabertura e o recomeço do turismo - "o futuro [do turismo] é agora (World Tourism Organization, 2020)". Resta saber com quais referentes, ideias e engajamentos as mobilidades turísticas pós-pandemia serão (re)produzidas e (re)inventadas.

\section{REFERÊNCIAS}

Agência IBGE de Notícias (2018). Internet chega a três em cada quatro domicílios do país. Agência IBGE Notícias. Recuperado de: https://agenciadenoticias.ibge.gov.br/ agencia-sala-de-imprensa/2013-agencia-de-noticias/releases/23445-pnad-continuatic-2017-internet-chega-a-tres-em-cada-quatro-domicilios-do-pais.

Allis, T. (2016). Em busca das mobilidades turísticas. Plural, 23, 94-117.

Allis, T. (2018). Movilidad y Turismo. In Zunino Singh, D.; Giucci, G. \& Jirón, P. Términos clave para los estudios de movilidad en América Latina. B. Aires. Biblos. (pp. 131-138).

Amin, A. \& Thrift, N. (2002). Cities: Reimagining the Urban. Cambridge: Polity Press.

Arellano, A. (2004). Bodies, spirits, and Incas: performing Machu Picchu. In Sheller, M. \& Urry, J. (Eds.), Tourism mobilities: places to play, places in play. Routledge. (pp. 67-77).

Bauman, Z. (2000). Liquid Modernity. Cambridge: Polity Press.

Bærenholdt, J. O. \& Haldrup, M. (2004). On the track of the Vikings. In Sheller, M. \& Urry, J. (Eds.), Tourism mobilities: places to play, places in play. Routledge. (pp. 78-89).

Brouder, P.; Teoh, S.; Salazar, N. B.; Mostafanezhad, M.; Mei Pung, J.; Lapointe, D.; HigginsDesbiolles, F.; Haywood, M.; Hall, C. M. \& Clausen, H. B. (2020). Reflections and discussions: tourism matters in the new normal post COVID-19. Tourism Geographies. DOI: $10.1080 / 14616688.2020 .1770325$.

Cave, J. \& Dredge, D. (2020). Regenerative tourism needs diverse economic practices. Tourism Geographies, DOI: 10.1080/14616688.2020.1768434.

Chatterton, P. \& Hollands, R. (2003). Urban Nightscapes: youth cultures, pleasure spaces and corporate Power. London: Routledge.

Cohen, E. \& Cohen, S. A. (2015). A mobilities approach to tourism from emerging world region. Current Issues in Tourism, 18(1), 11-43.

Coleman, S. \& Crang, M. (2002a). Grounded Tourists, Travelling Theory. In Coleman, S. \& Crang, M. (Eds.). Tourism: Between Place and Performance. Oxford: Berghahn.

Coleman, S. \& Crang, M. (2002b). Tourism: Between Place and Performance. Oxford: Berghahn.

Coles, T. (2015). Tourism mobilities: still a current issue in tourism? Current Issues in Tourism, 18(1), 62-67. 
Coles, T.; Hall, C. M. \& Duval, D. T. (2005). Mobilizing Tourism: A Post-disciplinary Critique, Tourism Recreation Research, 30(2), 31-41.

Corbin, A. (1994). The Lure of the Sea: The Discovery of the Seaside in the Western World, 1750-1840. Berkeley: University of California Press.

Corbin, A. (2004b). Sensing Tourist Spaces. In Minca, C. \& Oakes, T. (Eds.), Tourism and the Paradox of Modernity. Minneapolis: University of Minnesota Press.

Cresswell, T. (2010). Mobilities I: Catching up. Progress in Human Geography, 35(4) 550-558.

Cutill, V. (2004). Little England's global conference centre: Harrogate. In Sheller, M. \& Urry, J. (Eds.). Tourism mobilities: places to play, places in play. Routledge. (pp. 55-66)

Degen, M. (2004). Barcelona's games: the Olympics, urban design, and global tourism. In Sheller, M. \& Urry, J. (Eds.). Tourism mobilities: places to play, places in play. Routledge. (pp. 130-142)

Díaz Soria, I. \& Llurdés Coit, J. C. (2013). Reflexiones sobre el turismo de proximidad como una estrategia para el desarrollo local. Cuadernos De Turismo, 32, 65-88.

Duffy, R. (2004). Ecotourists on the beach. In Sheller, M. \& Urry, J. (Eds.). Tourism mobilities: places to play, places in play. Routledge. (pp. 32-43).

Edensor, T. (1998). Tourists at the Taj: Performance and Meaning at a Symbolic Site. London: Routledge.

Edensor, T. (2004). Reconstituting the Taj Mahal: tourist flows and glocalization. In Sheller, M. \& Urry, J. (Eds.). Tourism mobilities: places to play, places in play. Routledge. (pp. 103-115).

Elliot, A., \& Urry, J. (2010). Mobile Lives. London: Routledge.

Federal Aviation Administration (June, 2019). Air Traffic by the numbers. Recuperado de:https://www.faa.gov/air_traffic/by_the_numbers/media/Air_Traffic_by_the_ Numbers_2019.pdf.

Featherstone, M. (1991). Consumer Culture and Postmodernism. London, Newbury Park, CA: Sage Publications.

Florida, R. (2002). The rise of the creative class. New York: Basic Books.

Freire-Medeiros, B. (2009). The favela and its touristic transits. Geoforum 40 (4), 580-588

Freire-Medeiros, B. (2013). Touring Poverty. New York: Routledge.

Freire-Medeiros, B. \& Name, L. (2017) Does the future of the favela fit in an aerial cable car? Examining tourism mobilities and urban inequalities through a decolonial lens, Canadian Journal of Latin American and Caribbean Studies / Revue canadienne des études latino-américaines et caraïbes, 42 (1), 1- 16, DOI: https://doi.org/10.1080/08263663.2017.1281944

Freire-Medeiros, B., Telles, V. \& Allis, T. (2018). Apresentação: por uma teoria social on the move. Dossiê mobilidades. Tempo Social, 30 (2), 1-16.

Freitas, J.A. (2018). A invenção da cidade inteligente Rio: uma análise do Centro de Operações Rio pela lente das mobilidades (2010-2016). Tese de doutorado. Programa de PósGraduação em História, Política e Bens Culturais. Centro de Pesquisa e Documentação de História Contemporânea. Fundação Getúlio Vargas. Rio de Janeiro.

Gale, T. (2009). Urban Beaches, Virtual Worlds and The End of Tourism, Mobilities, 4(1), 119-138.

Galvani, A.; Lew, A. A. \& Perez, M. S. (2020): COVID-19 is expanding global consciousness and the sustainability of travel and tourism, Tourism Geographies, DOI: $10.1080 / 14616688.2020 .1760924$. 
Germann-Molz, J. (2004). Playing online and between the lines: round-the-world websites as virtual places to play. In Sheller, M. \& Urry, J. (Eds.). Tourism mobilities: places to play, places in play. Routledge. (pp. 169-180).

Germann-Molz, J. (2009) Representing pace in tourism mobilities: staycations, slow travel and the Amazing Race, Journal of Tourism and Cultural Change, 7 (4), 270-286, DOI: $10.1080 / 14766820903464242$.

Gössling, S.; Scott, D. \& Hall, C. M. (2020). Pandemics, tourism and global change: a rapid assessment of COVID-19. Journal of Sustainable Tourism, DOI: $10.1080 / 09669582.2020 .1758708$.

Gretzel, U. (2010). Travel in the Network: Redirected Gazes, Ubiquitous Connections and New Frontiers. In M. Levina \& G. Kien (Eds.). Post-global Network and Everyday Life (pp. 41-58). New York: Peter Lang.

Hall, C. M. (2004). Tourism: Rethinking the Social Science of Mobility. Harlow. Pearson Education.

Hall, C. M. (2015). On the mobility of tourism mobilities. Current Issues in Tourism, 18(1), 7-10.

Halgreen, T. (2004). Tourists in the concrete desert. In Sheller, M. \& Urry, J. (Eds.). Tourism mobilities: places to play, places in play. Routledge. (pp. 143-154).

Hall, C. M.; Sharples, L.; Mitchell, R.; Macionis, N. \& Cambourne, B. (2003). Food Tourism Around the World. Amsterdam: Butterworth Heinemann.

Hannam, K. (2009). The end of Tourism? Nomadology and the mobilities paradigm. In Tribe, J. (Ed.). Philosophical Issues in Tourism (p. 101-116). Bristol: Channelview.

Hannam, K., Butler, G., \& Paris, C. (2014). Developments and Key Concepts in Tourism Mobilities. Annals of Tourism Research, 44(1), 171-185.

Hannam K., Sheller M., \& Urry, J. (2006) Mobilities, Immobilities and Moorings. Mobilities, 1,1-22.

Harrison, D. (2017). Tourism, mobilities and paradigms. Tourism Management, 63, 329-337.

Hetherington, K. (1997). Place of Geometry: the materiality of place. In Hetherington, K., \& Munro, R. (eds). Ideas of Difference. Oxford: Blackwell.

Horwitz, J., \& Singley, P. (Eds). (2004). Eating Architecture. Cambridge, MA: M.I.T. Press.

International Air Transport Association (2019). World Air Transport Statistics 2019. Recuperado de: https://www.iata.org/contentassets/a686ff624550453e8bf0c9b3f7f0ab26/wats2019-mediakit.pdf. Acesso em: 20 jan. 2020.

Internet World Stats. (online). World internet usage and population statistics. Recuperado de: https://www.internetworldstats.com/stats.htm.

Jaguaribe, B., \& Hetherington, K. (2004). Favela tours: indistinct and mapless representations of the real in Rio de Janeiro. In Sheller, M. \& Urry, J. (Eds.). Tourism mobilities: places to play, places in play. Routledge. (pp. 155-166).

Judd, D., \& Fainstein, S. (1999). The Tourist City. New Haven, CT: Yale University Press.

Junemo, M. (2004). Let's build a palm island!: playfulness in complex times. In Sheller, M. \& Urry, J. (Eds.). Tourism mobilities: places to play, places in play. Routledge. (pp. 181-191). Routledge.

Kaufmann, V. (2009), Mobility: trajectory of a concept in the social sciences. In Mom, G. G. Pirie \& L. Tissot (Eds.). Mobility in history: the state of the art in the history of transport, traffic, and mobility. Neuchâtel, Alph, pp. 41-60.

Klein, N. (2000). No Logo. London: Flamingo.

Koens, K., Postma, A., \& Papp, B. (2018). Is Overtourism Overused? Understanding the Impact of Tourism in a City Context. Sustainability, 10, 4384. 
Kunz, J. (2014). As mobilidades turísticas como objeto de pesquisa: um panorama dos periódicos estrangeiros (2000-2014). Revista Rosa dos Ventos - Turismo e Hospitalidade, 7(3), 377-391.

Lai, C-L (2004). Art exhibitions travel the world In Sheller, M. \& Urry, J. (Eds.). Tourism mobilities: places to play, places in play. Routledge. (pp. 90-102).

Lash, S. \& Urry, J. (1993). Economies of Signs and Space. Sage.

Larsen, J. \& Urry, J. (2011). The tourist gaze 3.0. Routledge.

Lennon, J., \& Foley, M. (2000). Dark Tourism: the attraction of death and disaster. London: Continuum.

Lipovetsky, G., \& Serroy, J. (2015). La estetización del mundo: vivir en la época del capitalismo artístico. Barcelona: Anagrama (Colleción Argumentos).

Löfgren, O. (1999). On holiday: a history of vacationing. Berkeley: University of California Press. . (2004). Narrating the Tourist Experience. In S. B. Gmelch (Ed.). Tourists and Tourism: A Reader. Long Grove, IL: Waveland Press.

. (1992). Empty Meeting Grounds. London: Routledge.

Macnaghten P. \& Urry, J. (1998). Constested natures. Sage.

MacCannell, D (1976). The tourist: a new theory of the leisure class. New York: Schocken Books.

Menezes, P. (2015). Entre o fogo cruzado e o campo minado: uma etnografia do processo de pacificação de favelas cariocas. Tese de doutorado. Instituto de Estudos Sociais e Políticos. Universidade do Estado do Rio de Janeiro. Rio de Janeiro.

Minca, C., \& Oakes, T. (2004a). Introduction: Travelling Paradoxes: remapping tourism. In C. Minca \& T. Oakes (Eds.). Tourism and the Paradox of Modernity. University of Minnesota Press.

Minca, C., \& Oakes, T. (Eds.) (2004b). Tourism and the Paradox of Modernity: remapping tourism. Minneapolis: University of Minnesota Press.

Moraes, C. M. S. (2016). Turismo em favelas: notas etnográficas sobre um debate em curso. Plural, 23(2), p. 65-93.

Moraes, C. M. S. (2017). Favelas Ecológicas: passado, presente e futuro do turismo em favelas. Tese de doutorado. Programa de Pós-Graduação em História, Política e Bens Culturais. Centro de Pesquisa e Documentação de História Contemporânea. Fundação Getúlio Vargas. Rio de Janeiro.

Moraes, C. M. S. (2018). Urry, John. What is the future? Tempo Social, 30(2), 317-322. Recuperado de: https://doi.org/10.11606/0103-2070.ts.2018.142099.

Nevarez, L. (2002). New Money, Nice Town: How Capital Works in the New Urban Economy. New York: Routledge.

Nogueira, M.A.F. (2015) Mobilidade em potência e discurso publicitário na sociedade contemporânea globalizada. Brasil, 1982-2014. Tese de doutorado. Programa de Pós-Graduação em História, Política e Bens Culturais. Centro de Pesquisa e Documentação de História Contemporânea. Fundação Getúlio Vargas. Rio de Janeiro.

Nogueira, M.A.F \& Moraes, C. M. S. (Eds.) (2020). Brazilian mobilities. London: Routledge.

Ringer, G. (Ed.) (1998). Destinations. London: Routledge.

Roche, M. (2000). Mega-Events and Modernity: Olympics and Expos in the Growth of Global Culture. London: Routledge.

Rojek, C., \& Urry, J. (1997). Transformations of Travel and Theory. In C. Rojek \& J. Urry (Eds.). Touring Cultures: Transformations of Travel and Theory. London: Routledge. 
Rothman, H. (2002). Neon Metropolis: How Las Vegas Started the Twenty-First Century. New York: Routledge.

Sharpley, R. (2004). Islands in the sun: Cyprus. In Sheller, M. \& Urry, J. (Eds.). Tourism mobilities: places to play, places in play. Routledge. (pp. 22-31).

Sheller, M. (2000). Democracy after Slavery: black publics and peasant radicalism in Haiti and Jamaica. London: Macmillan.

Sheller, M. (2003a), Consuming the Caribbean: From Arawaks to Zombies. London, New York: Routledge.

Sheller, M. (2003b). Creolization in Global Culture. In S. Ahmed, A. M. Fortier, C. Castaneda \& M. Sheller (Eds.), Uprootings/Regroundings: Questions of Home and Migration. Oxford: Berg.

Sheller, M. (2004a). Demobilizing and remobilizing Caribbean paradise. In Sheller, M. \& Urry, J. (Eds.). Tourism mobilities: places to play, places in play. Routledge. (pp. 13-21).

Sheller, M. (2004b). Natural Hedonism. In D. Duval (Ed.), Tourism in the Caribbean. London, New York: Routledge.

Sheller, M. (2014). Sociology after the Mobilities Turn. In Adey, P.; Bissel, K.; Hannam D. \& Sheller, M (Eds.). The Routledge Handbook of Mobilities. London: Routledge, p. 45-54.

Sheller, M. (2020a) Island Futures: Caribbean Survival in the Anthropocene. Durham and London: Duke University Press.

Sheller, M. (2020b). Reconstructing Tourism in the Caribbean: connecting pandemic recovery, climate resilience, and sustainable tourism through mobility justice. Journal of Sustainable Tourism, Online first (July, 2020) doi.org/10.1080/09669582.2020.1 791141.

Sheller, M. \& Urry, J. (2000). The City and the Car. International Journal of Urban and Regional Research, 24, 737-757.

Sheller, M. \& Urry, J. (2006). The new mobilities paradigm. Environment and Planning A, $38,207-226$

Sheller, M. \& Urry, J. (2003). Mobile Transformations of Public and Private Life. Theory, Culture and Society, 20, 107-125.

Shields, R. (2004). Surfing: global space or dwelling in the waves? In Sheller, M. \& Urry, J. (Eds.). Tourism mobilities: places to play, places in play. Routledge. (pp. 44-51).

Smith, V. (Ed.) (1989). Hosts and Guests: the Anthropology of Tourism. Philadelphia: University of Pennsylvania Press.

Sullivan K. (2004). Atomica world: the place of nuclear tourism. In Sheller, M. \& Urry, J. (Eds.). Tourism mobilities: places to play, places in play. Routledge. (pp. 192-204).

Sum, N-L. \& So M.-C. (2004). The paradox of a tourist centre: Hong Kong as a site of play and a place of fear. In Sheller, M. \& Urry, J. (Eds.). Tourism mobilities: places to play, places in play. Routledge. (pp. 119-130).

Tsionas, M. G. (2020). COVID-19 and gradual adjustment in the tourism, hospitality, and related industries. Tourism Economics. doi:10.1177/1354816620933039

United Nations High Commission for Refugees (n.d). Figures at a glance. Recuperado de: https://www.unhcr.org/figures-at-a-glance.html.

Urry, J. (1995). Consuming places. Routledge.

Urry, J. (1996). O olhar do turista. São Paulo: Sesc, Studio Nobel.

Urry, J. (2000). Sociology Beyond Societies: Mobilities for the Twenty-First Century. London: Routledge. 
Urry, J. (2002). The tourist gaze. 2. ed. London: Thousang Oaks: Sage.

Urry, J. (2003a). Global Complexity. Cambridge: Polity Press.

Urry, J. (2003b), Social Networks, Travel and Talk. British Journal of Sociology, 54, 155-175.

Urry, J. (2004). Death in Venice. In Sheller, M. \& Urry, J. (Eds.). Tourism mobilities: places to play, places in play. Routledge. (pp. 205-215).

Urry, J. (2007). Mobilities. Cambridge: Polity Press.

Urry, J. (2016). What is the future? Cambridge: Polity.

Urry, J. \& Rojek, C. (Eds.) (1997). Touring cultures: Transformations of Travel and Theory. Routledge.

World Travel and Tourism Council (n.d). Economic Impact Reports. Recuperado de: https://wttc.org/Research/Economic-Impact.

World Tourism Organization (2020, May 20). The future is now! UNWTO recognizes world's best innovators facing up to COVID-19. Recuperado de: https://www.unwto.org/ news/the-future-is-now-unwto-recognizes-world $\% \mathrm{E} 2 \% 80 \% 99 \mathrm{~s}$-best-innovatorsfacing-up-to-covid-19.

Zukin, S. (2003), Home Shopping in the Global Marketplace. Les sens de mouvement colloque, Cerisy-la-salle, France, June.

Zunino Singh, D., Giucci, G., \& Jirón, P. (2018). Términos clave para los estudios de movilidad en América Latina. B. Aires: Biblos.

Recebido em: $15 / 06 / 2020$

Aprovado em: 10/07/2020

\section{CONTRIBUIÇÃo}

Thiago Allis: Realização da revisão bibliográfica e fundamentação teórica, revisão crítica do manuscrito, redação do manuscrito, adequação do manuscrito às normas da RTA $\mathrm{e}$ tradução e revisão dos originais para a Língua Portuguesa.

Camila Moraes: Realização da revisão bibliográfica e fundamentação teórica, revisão crítica do manuscrito, redação do manuscrito, adequação do manuscrito às normas da RTA e tradução e revisão dos originais para a Língua Portuguesa.

Mimi Sheller: Definição do problema de pesquisa e objetivos, desenvolvimento da proposição teórica, realização da revisão bibliográfica e fundamentação teórica, escolha dos procedimentos metodológicos, revisão crítica do manuscrito, redação do manuscrito e revisão do texto do resumo em inglês. 